Int. J. Electrochem. Sci., 15 (2020) $1904-1914$

\title{
Determination of Bisphenol in Food Samples Using an Electrochemical Method Based on Modification of a Carbon Paste Electrode with CdO Nanoparticle/Ionic Liquid
}

\author{
Farzaneh Mehri-Talarposhti ${ }^{1}$, Azade Ghorbani-HasanSaraei ${ }^{2,}{ }^{*}$, Hassan Karimi-Maleh ${ }^{3,4,5 *}$, Leila \\ Golestan $^{1}$, Seyed-Ahmad Shahidi ${ }^{2}$ \\ ${ }^{1}$ Department of Food Hygiene, Ayatollah Amoli Branch, Islamic Azad University, Amol 46311- \\ 39631, Mazandaran, Iran \\ ${ }^{2}$ Department of Food Science and Technology, Ayatollah Amoli Branch, Islamic Azad University, \\ Amol 46311-39631, Mazandaran, Iran \\ ${ }^{3}$ School of Resources and Enviroment, University of Electronic Science and Technology of China, \\ P.O. Box 611731, Xiyuan Ave, Chengdu, P.R. China \\ ${ }^{4}$ Department of Chemical Engineering, Laboratory of Nanotechnology, Quchan University of \\ Technology, Quchan, Iran \\ ${ }^{5}$ Department of Chemical Sciences, University of Johannesburg, P.O. Box 17011, Doornfontein \\ Campus, 2028 Johannesburg, South Africa \\ *E-mail: $\underline{\text { Azade380@yahoo.com (AGS); hassan@uestc.edu.cn and hassan.karimi.maleh@gmail.com }}$ \\ (HKM)
}

doi: $10.20964 / 2020.03 .16$

Received: 2 October 2019 / Accepted: 9 December 2019 / Published: 10 February 2020

\begin{abstract}
An electroanalytical sensor for bisphenol A has been constructed through modification of a carbon paste electrode with a cadmium oxide nanoparticle (CdO/NPs) and 1-methyl-3-octylimidazolium tetrafluoroborate as an ionic liquid (MOITFB). The CdO/NPs were prepared and characterized using FESEM and XRD techniques, and were also indicated to have particle diameters less than $45 \mathrm{~nm}$. The resulting sensor (CdO/NPs-MOITFB-CPE) was used for analyzing the trace level of bisphenol A in the concentration ranged from $0.01 \mu \mathrm{M}$ to $280.0 \mu \mathrm{M}$, and a detection limit of $0.001 \mu \mathrm{M}$ was determined for that. The signal recorded for bisphenol A using the modified CPE, was found to be improved 3.64 times as compared to unmodified CPEs, and the oxidation potential of bisphenol A was also decreased to 170 $\mathrm{mV}$. Furthermore, the selectivity of the CdO/NPs-MOITFB-CPE to common interfering substances was found to be at a good level. The CdO/NPs-MOITFB-CPE showed a good performance in the determination of bisphenol $\mathrm{A}$ in food samples such as tuna fish, tomato paste, and stew with acceptable recovery data.
\end{abstract}

Keywords: Bisphenol A, $\mathrm{CdO}$ nanoparticle, 1-methyl-3-octylimidazolium tetrafluoroborate, Electrochemical food sensor 


\section{FULL TEXT}

(C) 2020 The Authors. Published by ESG (www.electrochemsci.org). This article is an open access article distributed under the terms and conditions of the Creative Commons Attribution license (http://creativecommons.org/licenses/by/4.0/). 